\title{
The Mischief of Mobile Phones as Caregivers or Babysitters for Children with Collaborative Developmental Delays
}

\author{
Ravneet Chawla \\ Ph.D., Assistant Professor in Human Development and Family Relations, Government College of Education, \\ Panjab University, Chandigarh, India.E mail; hdfr7dr.ravneet@yahoo.com
}

\begin{abstract}
The boon of connectivity using mobile phones is rather a bane in most family situations. The cases related to early dependence/addiction of mobile phones with the counselors and clinicians are rising alarmingly. Giving mobile phones to children is an easy way for engaging in various applications or other visual material which stimulates and involves the tender but vulnerable minds. Managing children with delayed milestones with regard to speaking, mobility, overall body control and social participation, is very challenging for the parents, furthermore for dual working parents. The study was done to assess the damage on children up to the age of 14 years by seeking inputs from clinical psychologists, school counselors and parents of children with developmental delay $(\mathrm{N}=120)$ over the period of 1 month. Case reports with the clinical psychologists were analysed. Inputs of school counselors/teacher report were studied. The parents were interviewed using semi structured interview schedule. The findings showed that most of these children had more than one developmental issues. Autism cases are on the rise, including secondary symptoms in some cases. Almost all parents reporting to clinicians admitted to using mobile phones to manage these children. Instead of one to one quality time for pro-active and purposive interactions which require dedication and focused time, mobile phones were making them indulge into poor and passive learning. The intervention suggestions included weeding out the mobile phone, practicing behavioral therapies involving active learning by simple instructions, expecting responses from children and using positive reinforcement. Use of music, dance, and storytelling, narrations on a concept or theme were expected to bring positive results. Polite public policy to keep out mobile phones can bring accepted change in working with children.
\end{abstract}

KEYWORDS: Collaborative developmental delays, active learning, passive learning, mobile addiction, vulnerable minds, autism, behavioural therapy

\section{Introduction}

Parents' distraction with mobile phones and other related devices is a growing concern. Much evidence has been collected on neglect towards children, affecting quality of bringing them up. The sensitivity is poor. There is passivity and inattentiveness (McCarthy 2016). Children miss on normal verbal expressions and mindful non-verbal gestures. The care-giver is missing even while being around. The parents/caregivers have certain personal traits and baggage that determines their conduct. The children of such setups end up exhibiting behavioural problems. Mothers and fathers have admitted to different kinds of 'technoference' in interpersonal relationships between the parents and children; more with mothers than with fathers (McDaniel and Radesky, 2017; Hynas 2018). A few behaviour disorders found were temper tantrums, frustration, whining, sulking and hyper activity. The challenge for bringing up children with developmental delays and those with collaborative health issues is too heavy on the parents/care-givers. Further the dynamics of family such as single parent family, low socio-economic status, ignorant parents, large families with over-engaged mothers, dual working families with long hours of being away to work, compound the situation. Developmental delay is a condition with significant delay in the process of development that requires special intervention to attain developmental milestones, interferes in the learning process, and demands special education and intervention to facilitate them in maximizing their language, perception, social development, emotional development, motor abilities and meta-cognition (Hassenfeld Children Hospital, n.d.). They exhibit burden on day to day skills in the early years. There can be delays in crawling or walking. They might find it difficult to cope with delay in language development (Blair,O 2017) and the change in social setups. Their speech could be delayed both in receptive and expressive aspects (Department of Education and Early Childhood Development, Government of Newfoundland, Labrador, Canada n.d.). 
While healthy parenting is interactive, mindful, involves direct eye-contact, meaningful touch and thoughtfully engaged care-givers who build up the child's behaviour and expression, both verbal and non-verbal. In a normal process children develop following the developmental principles in a sequential manner. The environment has much to contribute to reach their potentials. The concern is significant number of children reporting developmental delays. The association of these delays with collaborated disorders like ADHD, epilepsy, labour issues, anxiety disorders, conduct disorders, autism, and intellectual disability (Scott J.G., Mihalopoulos C, Erskine H.E., Roberts J., Rahman A. 2016) is furthermore challenging receptive and expressive aspects. Parents maybe escaping from children's issues and over involved with mobile devices, which allows them to be away from reading children's emotions. They are likely to be lower on understanding their children's mental states and intentions (Radesky, Schumacher and Zuckerman 2015).

The trend has reversed on the importance of mobiles among youth and the adults. In a news article (Medium German Broadcasting 2018) psychologist Catarina Katzer on parents if not responding to eye-contact to lead to physical and hormonal stress among children. A widely publicised protest by Emil Rustige in Hamburg, Germany in September 2018 caught attention globally wherein the kids revolted against parents to put down their phones (Anderson \& Petezinger 2018). 'Play with me, not with your phone' was the voice of the children with Emil. Face to face interactions are essential for healthy cognitive language and emotional development. But, the 'pacifier' use of mobiles is inappropriate. Options available on mobile like video games and other aggressive videos lead to restlessness.

There is seen a casual behaviour of care-givers while handling their children and intermittent fidgeting with their mobile devices (Radesky et. al. 2014). On meal-time observations at restaurants, it was found that the mothers were too engaged on their phones and declined proper availability to the toddlers. There is a warning to understand that the children may accept such behaviour while actually missing on language and on emotional bonding. Another study at Boston University Medical Campus 2014, points at inadequate balance exhibited by parents between the devices and their children. Some harms reported were - asthma, adolescent risk behaviour and obesity.

The concern on streamlining the use of smartphones by caregivers has caught attention by more researchers. Psychology Today on its blog shared some aspects studied on 7 months to 2-year-old infants and toddlers (Matthews 2017). Distress, weak exploratory behaviour, poor social-emotional functioning and parent-child interaction were pointed out. The children here pointed out negative and poor emotions even when their mothers put the phone down. AVG Technologies research in Amsterdam (AVG Now 2015) on 200 million monthly active users drew the challenge the child interprets to compete with the cell-phone and highlights the parents as poor role models. There was concern on mothers' low on predictability, attention and reliability leading to poor emotions. There is a hidden sadness in such children.

The vicious cycle of pleasure rewards sets in, described as dopamine effect, including diverted attention to someone else's phone nearby. Children look up to parents in a normal, gadget-free parenting/care-giving. Mobile media device use was found to be significantly associated with parentreported expressive speech delay in young children. Wallace (2017) showed speech delay reports from the parents to have let their babies play on an iPad. The menace of handheld device use and communication delays boggled the minds of professionals working in the area and set doubts to approve the length of exposures to these devices, if at all. Cheung et. al. (2017), in a study discussed brain and sleep patterns that undergo substantial developmental change during initial years. There was a concern on the impact that it caused to the brain and on cognition during this critical period of early development. The touch screen devices fascinate infants and toddlers for being very portable and allowing multiple settings. Problematic sleep has been studied longitudinally. There is an alarm about reduced sleep duration in the first two years of life on later developmental outcomes. The screens were strongly recommended to be out a child's bedroom.

Meta-analysis on chosen 20 studies among children between 6 and 19 concluded on detrimental effects on sleep. The average touch screen usage time was found to be 24.44 minutes. Every additional hour of tablet use decreased sleep by 15.6 minutes. The content of media could possibly 
elevate psychological and physiological arousals. The bright blue light from the screens was found to affect arousal levels. Another consequence was increased day time sleep, increased background TV exposure and thus leading to poor night time sleep. Cell phones emit radio-frequency electromagnetic radiation which can lead to cancer (Kalvi, H. n.d.). Mothers who used cell phones during pregnancy had children exhibiting hyper activity or other emotional or behavioural problems. Children with ADHD exhibit higher impulsivity, cannot remain still and are distracted (Pedersen 2018). Children with ADHD who also had higher levels of lead in their blood, had a link with more number of phone calls and time spent on the phone. Younger the child, the greater was said to be the risk of brain cancer and brain tumours (Johnson KJ, et al. 2017) at the National Center for Health Research, Washington, DC. These facts have been debated as cancer and other health problems usually show up many years later.

\section{Objectives}

- To assess the damage of mobile dependency on children between 2-13 years, under clinical care

- To assess the parent(s) contribution in the setback to the progress of children with developmental delays

\section{Methodology}

Sample selection: 120 toddlers, infants and children between the age 2 years to 13 years were identified with parents reporting delayed speech, restlessness and hyper-activity, isolated behaviour, blinking of eyes and other motor ticks and peculiar behaviour after seizures. They took initiative to visit a clinic for seeking remedy. They were concerned by pointers from family and/or school.

Tools used: Case reports with history, parental observations, mother/father/caregiver other than a parent report, purposive captured videos, live observations, teacher inputs, open ended interviews and findings by paediatric neurologist and clinical psychologist.

The cases were direct walk-ins, referrals from neurologists. They were first time visitors and review cases after 1/3/6/12 months. The patients were usually accompanied by the mother or both parents or one parent with grandmother or a sibling.

Inputs from four school counsellors were taken on understanding the incidence and readiness and provisions available to include such children in the schools they were working in.

\section{Results}

- The parents reported in distress and inquired on possibility of normalcy in their children's delays. The cases were from low income group (16), low middle income group (58), middle income group (33), upper middle income group (9) and high income group (4).

- The educational background of the parents was a barrier as those from low SES, were occupied at skills level, unware of the developmental delay. They had long work hours. In spite of intervention, they required repeated instructions to execute the strategies suggested. All the cases had issues on using mobiles, one or both parents distracted with the smart phones. There were cases causing marital conflict due to extreme usage of phone on the apps involving messaging, making and sharing videos, online shopping and listening to spiritual discourse. Many fathers had a complained about mothers making lengthy phone calls. Few mothers had complained about the fathers using adult website late at night. Many parents were addicted to games. Among cases reported in paediatric care, children were observed to be helplessly claiming the mobile phone of their parents. Those who showed parameters close to autism hardly made an eye contact with the persons present in the room.

- Temper tantrums could be observed on withdrawing the mobile. The toddlers did not realize the presence of others while hitting their mothers to snatch the phone.

- Toddlers were dependent on cell phones to accept meals.

- Few parents were pro-active in management of their children when they visited the psychologist for the first time. These parents were not so active on social media. These parents 
had reported better management of their child on $2^{\text {nd }}$ or $3^{\text {rd }}$ visit. Their behaviour was calm and they had resolved the panic. Also those cases which came for a follow on after a year had clear resolved and unresolved areas. They had put away the mobile phones from over handedness and the social interaction with the child had improved. However, the felt a block in their child making friends.

- The cases with hyper-active behaviour as a prognosis were highly significant on mobile dependence for involvement in aggressive video games. Such children were visibly restless; some of them reported destructive behaviour at home and in neighbourhood; their teacher reports endorsed their inattentiveness in class and attention seeking behaviour. Such parents needed psychotherapy in practicing low stimulation and creating calm, uninterrupted and uncluttered environment.

- The cases referred from neurology clinics with epilepsy also showed hyper-activity and consequent effect on classroom performance. The mobile was a major destructive agent. The parents were advised to follow medication and have more outdoor safe activities to make other joyful experiences.

- A peculiar case of a doctor mother who had over-expectations from the ten-year-old child was discussed. The child was very expressive, self-styled and reluctant to take instructions. On individual interaction and assessment, he was found to be high on IQ, had complaints about a gap between how parents thought about him, less family outings and over anxious mother. The parents were suggested to not suffocate the child with too many instructions, often appreciate him and function as pleasant parents.

- There was a borderline intellectual 8-year-old girl who had meek body language, average performance in academics but she loved to dance on certain songs available on a video browsing application.

- The counsellors were concerned on the growing restlessness and distraction among many school going children in early years. They had dealt with the global mess of few devastating online games leading to depression and death. Peer education and teacher alertness had to be used. According to them, most parents were on a denial of permissive mobile phone usage by their wards to entertain compulsive, misuse gadgets to do shortcuts in home tasks, fidgety body language in many children, and early exposure inappropriate videos. The schools were trying to go back to physical activities on a priority basis.

\section{Discussion}

The mobile devices and other screen engagements were found to be culprit of stealing the child of wholesome childhood experiences (McCrum 2015). The children with developmental delays were noticed of the challenge at different stages and the parents felt awkward and concerned without realizing how their distracted behaviour was stealing the warm parenting. The limitations on awareness, limited means, need for long working hours, stereotyped interference of grandparents, lack of an exemplary behaviour on the behalf of parents were concerns and required family therapy over the sessions. The teacher reports and observation sessions helped to decide the path of intervention. Cases with behavioural problems of parents were dealt with sensitive counselling. Children are likely to revolt on mobile withdrawal. Concern on the marketing strategies of E-learning products and gadgets is alarming. Fundamental risk with children who have developmental issues and the parents' escape in terms of helpless dependence on gadgets (Davidow 2012) can be reduced. These children need instructed play, exploring the nature around, enjoying physical toys and enjoying socializing with peers and grown-ups. Significant others and those in immediate environment be encouraged to interact with these borderline toddlers. There are interesting observations on the devices to be intuitive interfaces and versatile to draw children to solve puzzles, be entertained while on the go and children find these handy. Over-stimulation with media is feared to cause and imbalance in the cerebral cortex that can disturb the focus, memory and impulsivity in later life. In the article by Solon (2016), as mentioned, Maria Liu from UCB found more children to be myopic. Smith inquired on tablet use and rewards leading to child being driven for more use. Mark Livine questioned the authenticity of learning apps which may unintentionally the decreasing the over-all educational by 
enhancing stories using animations and sounds. A study at Stanford University in the US found that toddlers from disadvantaged families were behind their peers on language proficiency. They were kept busy with mobiles.

To manage the situation few changes can be inculcated. Airplane was recommended while a pregnant woman is around. Wireless networks and devices should be turned off when not in use. Turn off Wi-Fi router at bed time. Speaker phone, earphones creating distance between the body and the cell-phone, educating on manufacturer's advice, sharing information with friends, family and schools can be incorporated to keep out the harm. Morin, A. (n.d.), in an article, recommended using cellphone contracts for kids, especially for those struggled with impulse control. Using cell-phones during family time has been out-rightly discouraged (PTI News 2018).

Serve and return (conceptualized by the Center for Developing Child, Harvard University n.d.) to shape a healthy brain architecture. Appropriate adult responses build neural connections which develop communication and social skills. Care-givers should acknowledge an infant's babbles, gestures or cries. Absence of responsive relationships is a serious threat to child's development and well-being. The persistent absence of serve and return is a double loss to not receive positive stimulation; it rather leads to stress response.

\section{Conclusion}

The masses need to be educated on deviations in development and when to report. They can be educated on recording evidences and generating global information about the child when they visit a clinician. Outdoor supervised activities of the special children should be encouraged. The parents can regiment a day with 'no gadget time'. The paper pencil method of recording things can be revived. Indoor activities like story telling can help develop rich vocabulary and better verbal and non-verbal expressions. It also helps to have better emotional development. The parents must do correct narrative talking to stimulate the child's thought process; there should be questions seeking answers as well as answering the queries of the child on time. There must be unconditional acceptance of the child and of the life-situation that the family is going through. The non-judgemental response from the support team can help develop appreciation for good things in life and help focus on haves than have-nots. Behavioural therapy may include individual or family activities like walks, dancing and creating social time.

\section{The Way Forward}

The study can be pursued longitudinally. Home visits can bring in important understanding of dynamics of the family to offer doable paths in the near future. It can be repeated on one particular area of developmental delay or behavioural issues. The policy makers and the school programs should be well equipped and sensitized.

\section{References}

Anderson J. \& Petzinger J. 2018. "Kids are starting a revolution to get their parents to put down their phones." Quartz, September 11, 2018 https://qz.com/1384908/are-parents-suffering-from-smartphone-addiction/.

AVG Now. 2015. "Kids Competing with Mobile Phones for Parents' Attention." AVG Now, June $24,2015$. http://now.avg.com/digital-diaries-kids-competing-with-mobile-phones-for-parents-attention.

Blair, 0. 2017. "Child smartphonesmart phone and tablet usage linked to speech delays in toddlers." Independent, May 5, 2017. https://www.independent.co.uk/life-style/health-and-families/child-smartphone-tablet-usage-speech-delaystoddlers-a7719066.html.

Boston University Medical Campus. 2014. "Moms using mobile devices during mealtime interact less with children." Accessed on July 22, 2019. https://www.bumc.bu.edu/busm/2014/12/09/mobile-device-use-leads-to-fewinteractions-between-mother-and-child-during-mealtime/

Center on the Developing Child, Harvard University. n.d. "Key Concepts, Serve and Return." Accessed on July 22,2019 https://developingchild.harvard.edu/science/key-concepts/serve-and-return/.

Cheung et. al. 2017. "Daily touchscreen use in infants and toddlers is associated with reduced sleep and delayed sleep onset." Scientific Reports 7

Davidow, B. 2012. "Exploiting the neuroscience of internet addiction." The Atlantic, July 18, 2012, in Health. https://www.theatlantic.com/health/. 
Department of Education and Early Childhood Development, Government of Newfoundland and Labrador. "Developmental Delays." https://www.gov.nl.ca/eecd/k12/studentsupportservices/developmental/.

Hassenfeld Children Hospital. n.d. "Types of developmental delays in children." NYU Langone Health. https://nyulangone.org/conditions/developmental-delays-in-children/types.

Hynas, Charles. 2018. "Parents' excessive use of mobile phones is driving behavioural problems among children." The Telegraph, July 5, 2018. https:/www.telegraph.co.uk/news/2018/07/05/duty-care-mothersexcessive-use-mobile-phones-driving-behavioural/.

Johnson KJ, et al. 2017. "Pediatric cancer risk in association with birth defects: A systematic review." PLoS One.;12(7). doi:10.1371/journal.pone.0181246

Kalvi, H. n.d. "Children and cell phones: Is phone radiation risky for kids." National Center for Health Research. http://www.center4research.org/children-cell-phones-phone-radiation-risky-kids/.

Matthews, D. 2017. "Turn off that smartphone Mom and Dad. Parents on devices distress children and reduce their resilience." Psychology Today, Nov 23, 2017 http://www.psychologytoday.com/us/blog/going-beyondintelligence/201711/turn-smartphone-mom-and-dad.

McCarthy, Claire. 2016. "The latest dangerous addiction parents need to worry about: Mobile devices." Harvard Health Blog, May10, 2016. https://www.health.harvard.edu/blog/latest-dangerous-addiction-parents-need-worry-mobiledevices-201605109680.

McCrum, Kirstie. 2015. "Children reveal 'hidden sadness' of parents spending too much time on mobile phones in heartbreaking video." Mirror, August 10, 2015. https://www.mirror.co.uk/news/world-news/children-revealhidden-sadness-parents-6228329.

McDaniel B. T, \& Radesky J.S. 2017. "(May, 2017). Technoference: Parent distraction with technology and associations with child behaviour problems." Child Development .89 (1). DOI: 10.1111/cdev.12822.

Medium German Broadcasting. August 2018. "When Parents are Distracted by the Phone." Accessed on July $31,2019$. https://www.mdr.de/nachrichten/panorama/smartphone-gefahr-kinder-eltern-handy-100.html (Translated)

Morin. A. n.d. "Understood: Download cell phone contracts for kids." Accessed on July 19, 2019 https://www.understood.org/en/family/managing-everyday-challenges/daily-expectations-child/download-cellphone-contracts-for-kids-with-adhd

Pedersen, T. 2018. "Possible link between ADHD in children and cell phone use." Accessed on July $31,2019$. https://psychcentral.com/news/2013/04/21/possible-link-between-adhd-in-children-cell-phone-use/53948.htm.

PTI News. 2018. "Parents, take note! Smartphone usage during family time may affect your kids' behaviour." The Economic Times, Accessed on June 14, 2018. https://economictimes.indiatimes.com/magazines/panache/parentstake-note-smartphone-usage-during-family-time-may-affect-your-kids-behaviour/articleshow/64588157.cms?fro

Radesky et. al., 2014. "Patterns of Mobile Device Use by Caregivers and Children During Meals in Fast Food Restaurants." Pediatrics 3, no 4. e843-e849.

Radesky, Schumacher, Zuckerman B. 2015. "Mobile and Interactive Media Use by Young Children: The Good, the Bad, and the Unknown." Pediatrics Perspective 135, no. 1. 1-3

Scott JG, Mihalopoulos C, Erskine HE, Roberts J, Rahman A. 2016 "Childhood Mental and Developmental Disorders." In Mental, Neurological, and Substance Use Disorders: Disease Control Priorities, edited by Patel V, Chisholm D, Dua T, Laxminarayan R, Medina-Mora ME. Washington (DC): The International Bank for Reconstruction and Development / The World Bank

Solon, O. 2016. "Does spending too much time on smartphones and tablets damage kids' development?" Independent,. June 6, 2016. https://www.independent.co.uk/life-style/health-and-families/does-spending-too-much-time-onsmartphones-and-tablets-damage-kids-development-a7067261.html.

Wallace, Kelly. 2017. "Letting a baby play on an iPad might lead to speech delays." CNN Health, May $4,2017$. https://edition.cnn.com/2017/05/04/health/babies-screen-time-speech-delays-study/index.html. 